\section{International Scientific Journal Theoretical \& Applied Science}

p-ISSN: 2308-4944 (print) e-ISSN: 2409-0085 (online)

Year: $2014 \quad$ Issue: 12 Volume: 20

Published: $30.12 .2014 \quad$ http://www.T-Science.org
Meyrbek Inkarbekuly Azbergen

Professor, candidate of technical Sciences, Taraz state University M.Kh.Dulati, Kazakhstan azmeirbek@mail.ru

Sabira Aydarbekova graduate student

Taraz state University M.Kh.Dulati, Kazakhstan

SECTION 23. Agriculture. Agronomy. The technique.

\title{
THE SOIL OF THE ARABLE LAND AND CHANGE THEIR PROPERTIES
}

Abstract: The article presents the results of the study morphological characteristics of soils of arable lands and changes in them, the content of humus, nitrogen and phosphorus during the observation period. Presents experimentally determined in the studied soils the relationship between nitrogen, phosphorus and humus, with a recommendation by their description.

Key words: the soil of the arable land, morphological parameters, modify the properties of soil, humus, nitrogen, phosphorus.

Language: Russian

Citation: Azbergen MI, Aydarbekova S (2014) THE SOIL OF THE ARABLE LAND AND CHANGE THEIR PROPERTIES. ISJ Theoretical \& Applied Science 12 (20): 97-100. doi: http://dx.doi.org/10.15863/TAS.2014.12.20.21

УДК 631.4 (075.8)

\section{ПОЧВЫ ПАХОТНЫХ ЗЕМЕЛЬ И ИЗМЕНЕНИЕ ИХ СВОЙСТВ}

Аннотация: В статье приведены результаты исследования морфологических показателей почв пахотных земель и изменения в них содержания гумуса, азота и фосфора за период наблюдений. Представлены экспериментально установленные в изученных почвах зависимости между азотом, фосфором и гумусом, дана рекомендация по их описанию.

Ключевые слова: почвы пахотных земель, морфологические показатели, изменения свойств почв, гумус, азот, фосфор.

В результате хозяйственной деятельности человека в определенных природноклиматических условиях в почвенном покрове происходят изменения. Результаты периодических наблюдений за происходящими в почве процессами являются основой для решения многих практических задач селькохозяйственной деятельности.

В Республике Казахстан для наблюдения за изменениями, происходящими в почвенном покрове, учрежден «мониторинг земель» $[1,2,3]$. Мониторинг земель представляет собой систему базовых (исходных) оперативных, периодических наблюдений за качественным и количественным состоянием земельного фонда, проводимых в целях своевременного выявления происходящих изменений, их оценки, прогноза дальнейшего развития и выработки рекомендаций по предупреждению старения и последствий негативных процессов. Объектом мониторинга земель являются все земли Республики Казахстан независимо от форм собственности, целевого назначения и характера использования земель. Наиболее важным направлением мониторинга земель сельскохозяйственного назначения является ведение наблюдений на пахотных угодьях.

Мониторинг пахотных угодий ведется по природно-климатическим зонам (подзонам). Наблюдения за изменением состояния почв ведутся на специально заложенных для этих целей стационарных пунктах [4].

В работе приведены результаты изучения почв на орошаемых пашнях ПК «Бирлик» Жуалынского района Жамбылской области, где на заложенных стационарных пунктах (СЭП и ПСЭП) Жамбылским филиалом РГП «НПЦзем» проведены почвенные обследования. В процессе 
камеральной обработки определены морфологические показатели и физикохимические свойства почв.

На основании почвенного обследования почвенный покров участка СЭП представлен орошаемыми лугово-каштановыми, слабощебнистыми, тяжелыми суглинками. Рельеф участка слабоволнистый, предгорный, равниный. Угодья - орошаемые земли, занятые старыми яблоневыми насаждениями. Поверхность почвы трещиноватая, слабо выдержанная. Почвообразующими породами служат щебнистые, тяжелые суглинки, подстилаемые валунно-галечниковыми отложениями.

По морфологическим признакам на изученном участке можно выделить следующие генетические горизонты почв:

Горизонт Ап (0-29см) - темно-серый с бурым оттенком, тяжело суглинистый, комковато-зернистой структуры, слабо плотный, пористый, корней много, с включениями щебня, переход ясный.

Горизонт В1 (29-51 см) - серо-бурый, тяжелосуглинистый, комковато-ореховатый, сухой, пористый, среднее количество корней, с включениями щебня, переход постепенный.

Горизонт В2 (51-69см) серо-бурый с желтовым оттенком, тяжелосуглинистый, глыбисто-комковато-ореховатый, плотный, корней мало, переход постепенный.

Горизонт ВС (69-82см) - буро-желтый, комковато-ореховатый, среднесуглинистый, плотный, пористый, корни единичны, среднещебнистый, слабые ржавые пятна, переход заметный.

Горизонт С1 (82-120см) - буро-желтый, плотный, легкосуглинистый, слабо пористый, сильно щебенистый, ржаные пятна, переход ясный.

Горизонт $\mathrm{C} 2(120-170 \mathrm{~cm})$ представляет гравийно-галечниковые отложения с суглинистым заполнителем.

При исследовании агрохимических свойств почв пахотных земель особое внимание уделялось изучению изменения содержания в них гумуса, азота и фосфора - основных элементов, определяющих плодородие почвы [5, $6]$.

Гумус - это особая группа химических соединений, специфичная только для почвенных образований,. Он образуется из веществ растительных, животных и микробных остатков во взаимодействии с окружающей средой.

Основная масса азота почв сосредоточена в органическом веществе. Количество азота находится в прямой зависимости от содержания в почве органического вещества, и прежде всего гумуса. В большинстве почв этот химический элемент составляет 1/12-1/20 гумуса.

Фосфор, поглощаясь в больших количествах растениями, аккумулируется в верхних горизонтах почвы. Фосфор в почвах входит в состав органических и минеральных соединений, причем $50 \%$ запасов его сосредоточены в органическом веществе.

Комплекные исследования содержания гумуса, азота и фосфора в почвах пахотных земель ПК «Бирлик проводились в лаборатории «Геотехнологии» Таразского государственного университета имени М.Х.Дулати: химический анализ проводился на почвенных образцах, отобранных на СЭП, согласно [7]; изучение изменения содержания гумуса, азота и фосфора в почвах за предыдущие годы выполнено на основе использования фондовых материалов Жамбылского филиала РГП «НПЦзем».

Содержание гумуса определялось по методу Тюрина [8]. По результатам химанализа его содержание в пахотном горизонте (Ап) составило $2,33 \%$, в горизонте В1 - 1,62\%, а в горизонте В2 - 0,99\%.

Содержание валового азота определялось по методу Кьельдаля [9]. По результатам химанализа его содержание в пахотном горизонте Ап составило $0,177 \%$, а в горизонтах В1 и В2 соответственно - 0,120\% и 0,073\%.

Содержание валового фосфора определялось по методу Гинзбурга [10]. По результатам химанализа его содержание в пахотном горизонте составило 0,200\% , в горизонте В1 - 0,120\%, в горизонте В2 - 0,186\%.

Изучение изменения содержания гумуса, азота и фосфора в почвах в предыдущие (2008, 2003) годы, когда проводились почвенные обследования на данном участке, показало следующее:

- содержание гумуса составило: в 2008 году в пахотном горизонте (Ап) - 2,29\%, в горизонтах В1 и В2 - соответственно 1,66\% и 1,29\%, а в переходном горизонте ВC - 1,08\%; в 2003 году в горизонте Ап - 2,2\%, в горизонтах В1 и В2 $1,1 \%$, а в переходном горизонте ВС - 0,6\%.

- количество валового азота составило: в 2008 году в пахотном горизонте Ап - 0,173\%, в горизонте В1 - 0,069\%, а в горизонте В2 - 0,046\%; в 2003 году в горизонте Ап - 0,171\%, а в горизонтах В1 и В2 - 0,087\%.

- содержание валового фосфора составило: 2008 году в пахотном горизонте Ап - 0,139\%, в горизонте В1 - 0,139\%, а в горизонте В2 - 0,145\%; в 2003 году в пахотном горизонте Ап - 0,10\%, в горизонте В1 - 0,16\%, а в горизонте В2 - 0,14\%.

Динамика изменения содержания гумуса, азота и фосфора в почвах пахотных земель ПК «Бирлик» за изученный период представлена на рисунках 1-3. 


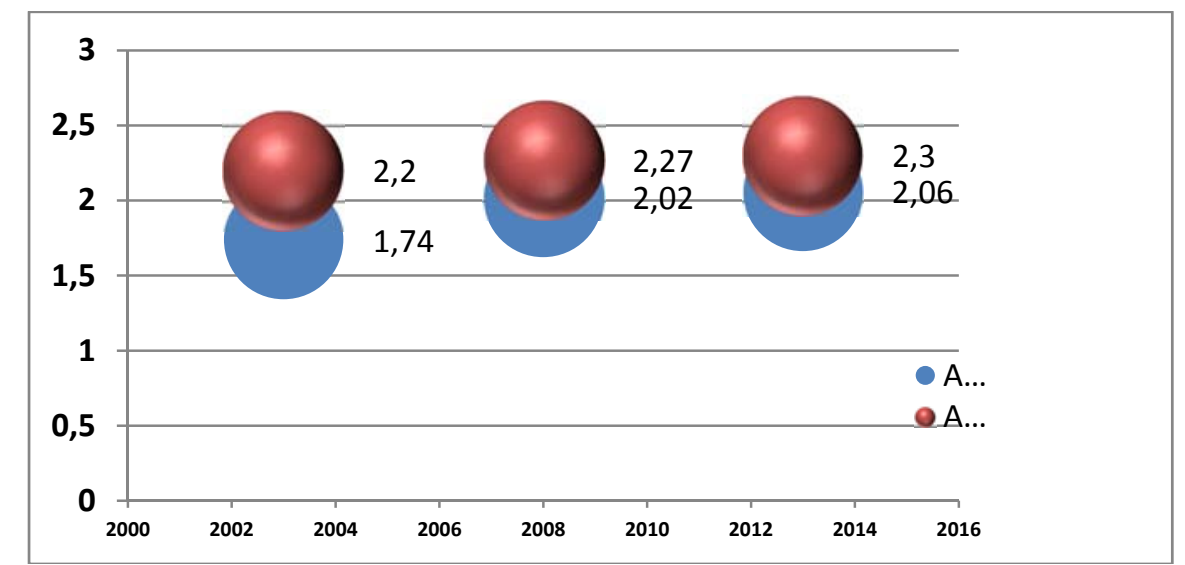

Рисунок 1 - Изменение содержания гумуса в почвах.

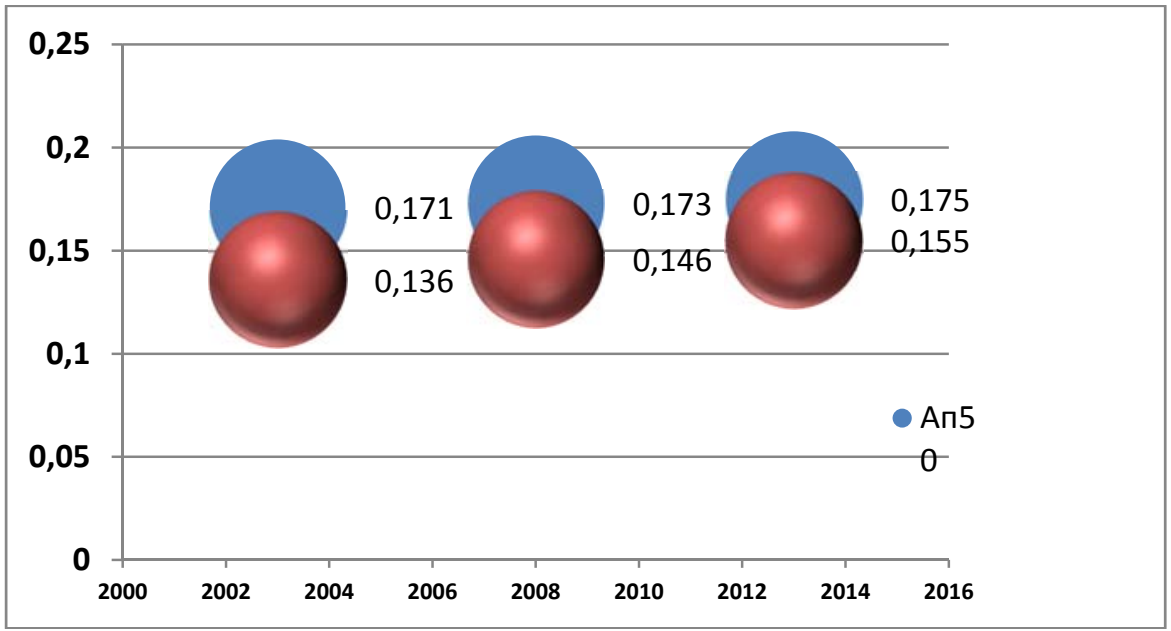

Рисунок 2 - Изменение содержания валового азота в почвах.

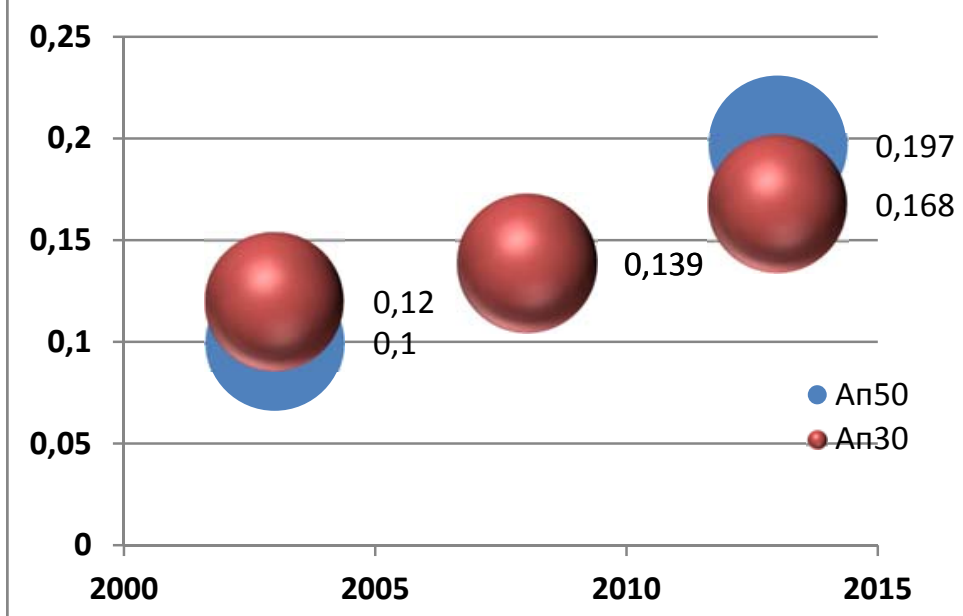

Рисунок 3 - Изменение содержания валового фосфора в почвах.

Зависимости валового азота и фосфора от содержания гумуса в почвах пахотного горизонта (рис.4-5), установленные экспериментальным путем, вполне определенны и согласуются с [11].
Очевидно, что полученные зависимости могут быть успешно описаны функциями линейного вида. 


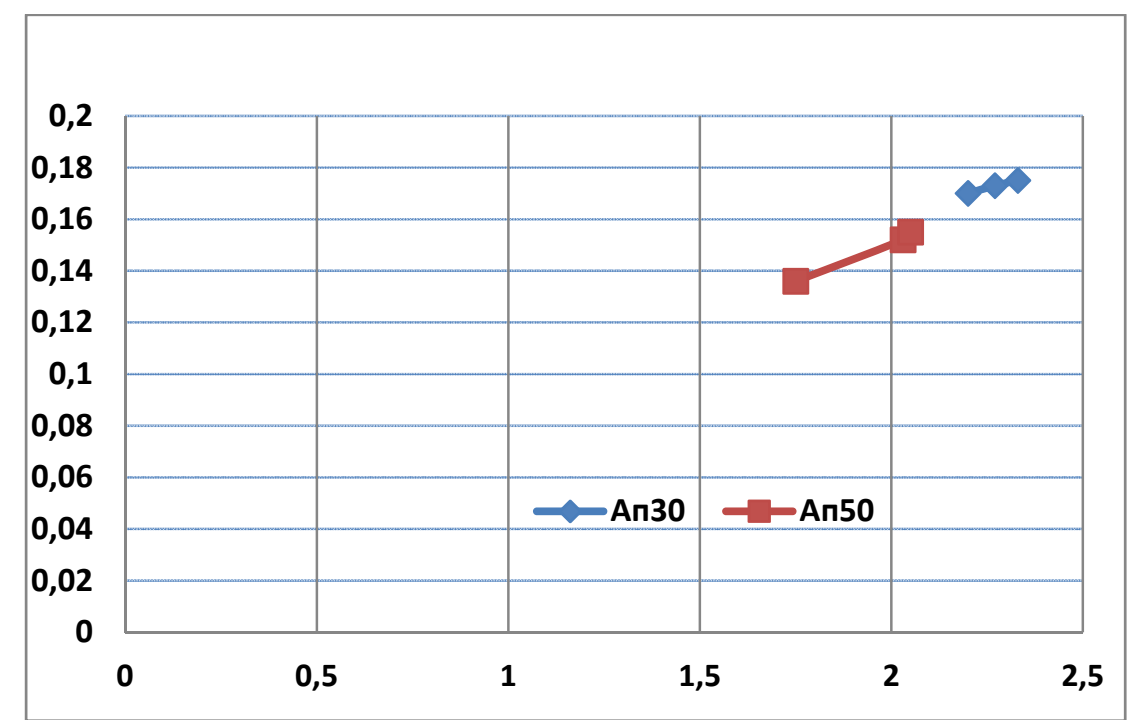

Рисунок 4 - Зависимость валового азота от содержания гумуса в почвах.

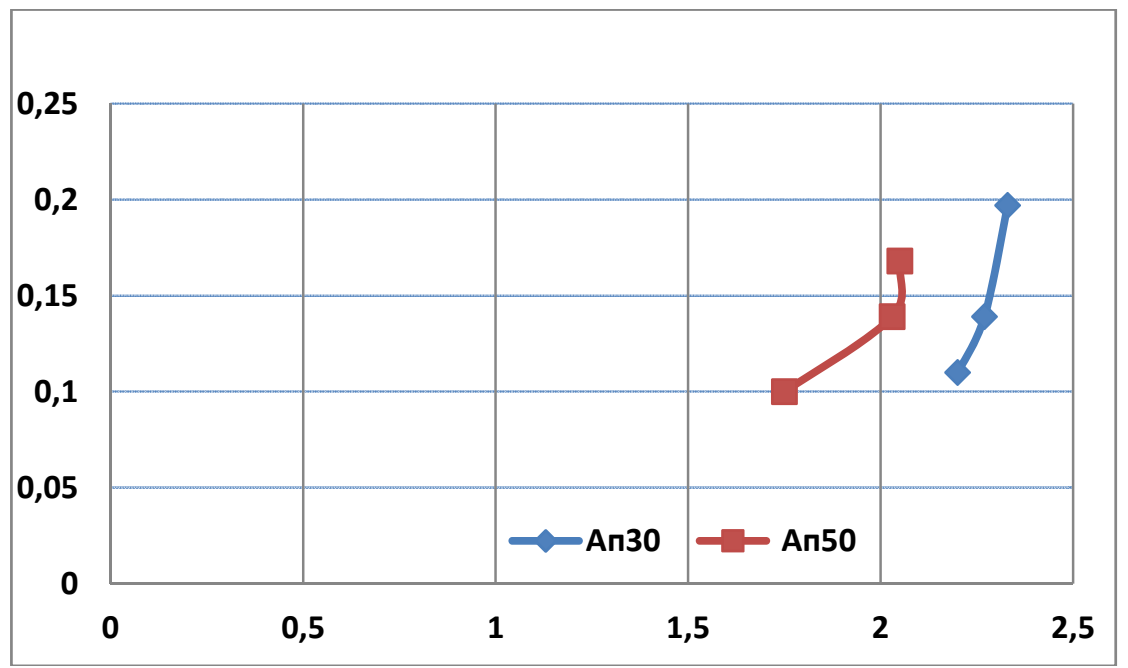

Рисунок 5 - Зависимость валового фосфора от содержания гумуса в почвах.

\section{References:}

1. (2003) Zemel'nyy Kodeks Respubliki Kazakhstan, utverzhdennyy 20 iyunya 2003 goda, pp.159, pp.179.

2. (1992) Postanovlenie Kabineta Ministrov Respubliki Kazakhstan ot 17 avgusta 1992 goda №683 «Ob utverzhdenii poryadka vedeniya monitoringa zemel' v Respublike Kazakhstan».

3. (2001) Postanovlenie Kabineta Ministrov Respubliki Kazakhstan ot 11 iyunya 2001 goda №800«O vnesenii izmeneniy i dopolneniy v nekotorye resheniya Pravitel'stva Respubliki Kazakhstan po regulirovaniyu zemel'nykh otnosheniy».

4. (2002) Nauchno-metodicheskie ukazaniya po monitoringu zemel' Respubliki Kazakhstan. Almaty, 2002.-108.

5. Kaurichev IS (1969) Pochvovedenie. Moscow: Kolos, 1969. - 540.
6. Val'kov VF, Kazeev KS, Kolesnikov SI (2004) Pochvovedenie: Uchebnik dlya vuzov. Moscow: IKTs «MarT», 2004. - 496.

7. (1998) Sbornik metodicheskikh ukazaniy po laboratornym issledovaniyam pochv i rastitel'nosti Respubliki Kazakhstan. - Almaty: 1998.

8. (1991) GOST 26213-91. Metod opredeleniya soderzhaniya gumusa $\mathrm{v}$ pochve.

9. (1984) GOST 26107-84. Metod opredeleniya valovogo azota.

10. (1984) GOST 26261-84. Metod opredeleniya valovogo fosfora.

11. (1989) Spravochnik po zemleustroystvu /L.Ya.Novakovskiy, V.M.Bulenok, Yu.M.Vagin i dr.: Pod red.L.Ya.Novakovskogo. - Kiev: «Urozhay», 1989. -352 . 